\title{
The potential for a concerted system for the rapid monitoring of excess mortality throughout Europe
}

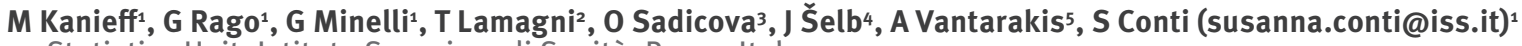

1. Statistics Unit, Istituto Superiore di Sanità, Rome, Italy

2. Health Protection Agency, London, United Kingdom

3. Health Protection Inspectorate, Tallin, Estonia

4. Institute of Public Health of the Republic of Slovenia, Ljubljana, Slovenia

5. University of Patras, Patras, Greece

Citation style for this article:

Kanieff M, Rago G, Minelli G, Lamagni T, Sadicova O, Šelb J, Vantarakis A, Conti S. The potential for a concerted system for the rapid monitoring of excess mortality throughout Europe. Euro Surveill. 2010;15(43):pii=19697. Available online: http://www.eurosurveillance.org/ViewArticle.aspx?Articleld=19697

We present the results of a survey conducted in the context of the project European Monitoring of Excess Mortality for Public Health Action (EuroMOMO), which is being conducted to develop a routine public health mortality monitoring system for the timely detection of excess deaths related to public health threats in Europe. The survey was conducted in 32 European countries using two questionnaires on: i) the existing and planned mortality monitoring systems, and ii) the routine collection of mortality data. Nine existing mortality monitoring systems were identified in seven countries (Belgium, Germany, France (two systems), Italy (two systems), Portugal, Spain, and Switzerland), as well as several systems that were in a pilot or planning state. Each system is described in detail. The results will be used for the subsequent phases of EuroMOMO, in particular for identifying the minimum requirements for the planned European system and for selecting countries to be included in the project's pilot phase.

\section{Introduction}

An important means of detecting potential health threats is mortality monitoring [1], which has been defined as 'the ongoing, systematic and timely collection, collation, analysis and interpretation of mortality data for public health, as well as the dissemination of information in order to take public health action' [2]. European Monitoring of Excess Mortality for Public Health Action (EuroMOMO) is a three-year project coordinated by the Statens Serum Institut, Denmark, and cofunded by the European Commission (EC), Directorate General for Health and Consumer Affairs (DG SANCO) [3]. The project has 22 partners, mainly national public health institutes, from 20 European countries. The objective is to develop a Europe-wide mortality monitoring system for detecting excess deaths related to possible public health threats across Europe, such as influenza and heat waves.

To reach this objective, it is necessary to have information on which resources are already available [2]. In particular, information is needed on existing mortality monitoring systems, which could be used to develop a model of a Europe-wide system and to determine whether or not the existing systems could be integrated into this system. Information is also needed on different countries' procedures for the routine collection of national mortality data (i.e. mortality data used for purposes such as demographics), to determine whether these procedures could be adapted for the timely monitoring of excess mortality.

Obtaining such information was the responsibility of EuroMOMO Work Package 4 (WP4: Inventory of the existing mortality monitoring systems in Europe), for which we conducted a survey in 2008 of existing systems for mortality monitoring and of the routine collection of mortality data in Europe. The results of this survey are described herein.

\section{Methods}

We performed the survey using two standardised electronic questionnaires on: i) existing systems for the timely monitoring of excess mortality; and ii) the routine national-level collection of mortality data. The questionnaires were developed in extensive discussions among WP4 members and other EuroMOMO participants.

The questionnaire on existing systems for the timely monitoring of excess mortality consisted of 49 questions, covering six areas:

- general characteristics of the system, including a question on whether the system was 'active', in a 'pilot phase', or 'planned';

- data collection;

- data analysis;

- data dissemination;

- data privacy;

- general strengths and weaknesses. 
On the questionnaire, a system for the timely monitoring of excess mortality was defined as: 'a system for rapidly collecting data on excess mortality for the purposes of public health surveillance, in addition to the routine collection of data on deaths which is generally performed by statistics institutes'.

The questionnaire on the routine national-level collection of mortality data consisted of $\mathbf{2 8}$ questions, covering four areas:

- general characteristics of data collection procedures;

- death certificate;

- data set;

- data dissemination.

This questionnaire was based on the questionnaire used by Eurostat [4].

The questionnaires were intended to be completed by contact persons in 32 countries. In most countries, each of the two questionnaires had a different contact person. Many contact persons were EuroMOMO participants. To identify the others, we relied on such sources as the EuroMOMO participants, our knowledge of existing mortality monitoring systems and their coordinators, our network of previously established work relationships, and, for the questionnaire on the routine collection of mortality data, on the list of national reference persons for Eurostat. We contacted these persons by email to determine their availability. If no response was received, we attempted to contact them again; if unsuccessful, we used the abovementioned sources to identify someone else. Persons declining participation were asked to suggest another person; if they did not, we again relied on the abovementioned sources to identify an alternative.

The questionnaires were sent by email in the first week of September 2008, asking for a reply by the end of the month. Reminders were sent until the completed questionnaires were received. A descriptive analysis of the responses to the questionnaires was performed, using the SPSS statistical package as support.

\section{Results}

Existing systems for the timely monitoring of excess mortality

Of the 28 countries that responded, seven had an existing system (defined as 'active' on the questionnaire). France and Italy had two systems each, giving a total of nine systems, all in western Europe (Figure).

\section{FIGURE}

Map of Europe indicating the status of the participating countries in terms of the existence of a rapid mortality surveillance system, EuroMOMO survey, $2008(\mathrm{n}=31)$

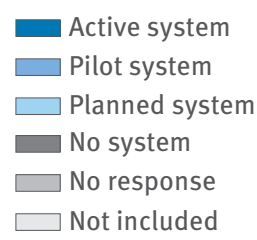

Non-visible countries $\square$ Luxembourg $\square$ Malta

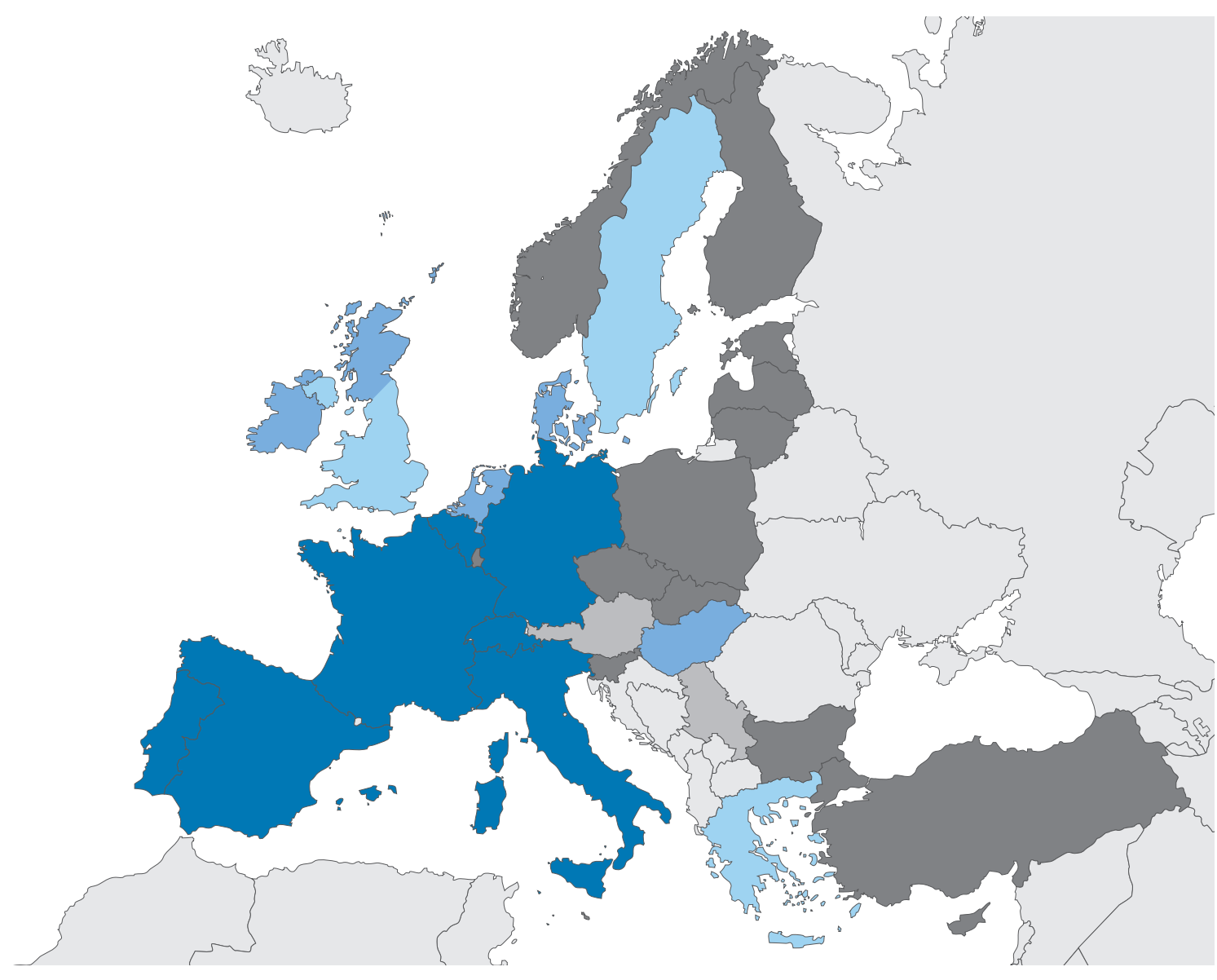

Note: A pilot system is in place in Berlin. 
The names of these systems (in their original language) are: Belgium (BE-MOMO), France (Surveillance de la Mortalité, herein referred to as 'France 1', and Surveillance de la Mortalité par Cause, herein referred to as 'France 2'), Germany (no official name reported), Italy (Sistema Nazionale di Sorveglianza Rapida della Mortalità, referred to as 'Italy 1', and Sorveglianza Epidemiologica Rapida della Mortalità nelle Città Capoluogo di Regione/Provincia Autonoma, herein referred to as 'Italy 2'), Portugal (no official name reported), Spain (MOMO: Monitorización de la Mortalidad Diaria), and Switzerland (Überwachung der Sterblichkeit (Exzessmortalität)).

\section{General characteristics of the}

\section{nine existing systems}

The stated objectives of the systems ranged from very generic to more specific, yet all of them seemed to conform with the general objective of EuroMOMO. All nine existing systems were created fairly recently, the first in Portugal in 2003. All but one system were managed by a health or statistics institute; for some systems, other institutions collaborated, e.g. statistics or health institutes or local registrar's offices. Six systems received specific funding, (i.e. not as part of the ordinary budget) from a public health institute: Belgium, Germany, France 1, France 2, Spain, and Italy 2. All but the Italy 2 system were active year-round.

\section{Data collection}

Data were provided by civil authorities (e.g. the General Registrar's Office) for all systems but the France 2 system (provided by health authorities), and through diverse means such as e-mail or web portal. The frequency at which data were provided ranged from real time (time of death +4 hours for France 2) to monthly (Italy 2). For four systems (Belgium, France 1, Germany, and Switzerland), it was mandatory to provide data.

\section{TABLE 1}

Coverage of the nine mortality surveillance systems (percentage of the national population) and percentiles of the time between death and data receipt, EuroMOMO survey, 2008

\begin{tabular}{|c|c|c|c|c|}
\hline \multirow[b]{2}{*}{ System } & \multirow{2}{*}{$\begin{array}{c}\text { Coverage (\% } \\
\text { of national } \\
\text { population) }\end{array}$} & \multicolumn{3}{|c|}{ Percentile } \\
\hline & & 25th & $\begin{array}{c}\text { 5oth } \\
\text { (median) }\end{array}$ & 75th \\
\hline Belgium & 100 & 5 days & 8 days & 11 days \\
\hline France 1 & 70 & NR & $\mathrm{NR}$ & $\mathrm{NR}$ \\
\hline France 2 & 1 & $\mathrm{NR}$ & 4 hours & $\mathrm{NR}$ \\
\hline Germany $^{\mathrm{a}}$ & 7 & $\mathrm{NR}$ & 10 days & $\mathrm{NR}$ \\
\hline Italy $1^{\mathrm{b}}$ & 20 & NR & 3 days & NR \\
\hline Italy 2 & 16 & NR & NR & NR \\
\hline Portugal & 100 & NR & 1 day & NR \\
\hline Spain & 57 & 1 day & 2 days & 4 days \\
\hline Switzerland & 100 & 4 days & 6 days & 8 days \\
\hline
\end{tabular}

$\mathrm{NR}=$ not reported

a Only covers the State of Hesse.

${ }^{b}$ Refers to the population aged $\geq 65$ years.
The geographic coverage was as follows: The systems Belgium, France 1, and France 2 covered the 'entire country'. The system in Germany collected data at the level of 'NUTS 1' (Nomenclature of Territorial Units for Statistics of Eurostat [5]), i.e. the major socio-economic regions. Italy 1 and Italy 2 covered the 'capital cities of Italy's 21 Regions and Autonomous Provinces', Portugal the 'entire country' and 'NUTS 1 ' and 'NUTS 2' (the basic regions for the application of regional policies), Spain covered 'NUTS 2' and 'NUTS 3' (small regions for specific diagnoses), 'certain towns/cities', and 'climatic zones', and Switzerland the 'entire country' and 'NUTS 1'. The coverage in terms of percentage of the national population was $100 \%$ for three systems, Belgium, Portugal and Switzerland (Table 1). The smallest geographic unit in the data received by the system was 'town/city' for Belgium, France 1, France 2, Italy 2, Spain, and Switzerland, 'NUTS 3' and 'administrative districts' for Germany, 'town/city' and 'census tract for the City of Rome' for Italy 1, and 'NUTS 1 and 2' for Portugal.

Regarding timeliness, the median time between death and receipt of the data by the system ranged from four hours (France 2) to 10 days (Germany) (Table 1). All systems received individual data. Although the specific variables collected differed (Table 2), all systems recorded some indication of age at death, as well as sex and date and place of death. The specific cause of death was recorded by one system (France 2), created specifically for this purpose. Five systems monitored excess influenza mortality, and seven systems collected climatic data (Table 3).

\section{Data analysis}

Data-quality control was performed by six systems, Belgium, France 1, France 2, Italy 1, Portugal, and Spain, in all cases at the central level. Six systems analysed the data by sex (Belgium, Italy 1, Italy 2, Portugal, Spain, and Switzerland). Regarding the indicators used, five systems, Germany, Italy 2, Portugal, Spain, and Switzerland, produced only absolute values (e.g. weekly number of deaths). The Belgian system produced crude rates only, whereas France 1 and France 2 also produced age-adjusted rates, and Italy 1 produced crude rates and age- and sex-adjusted rates. No system calculated the standardised mortality ratio. The Belgian system performed time series analyses only, France 1 and Italy 1 performed time series and mathematical models taking into account other variables, and the Spanish system performed time series, cumulative sum control chart (CUSUM) modification algorithm, and Kriging analysis.

\section{Data dissemination}

The eight systems that provided this information disseminated data through either a website or e-mail (Table 4). The frequency of dissemination ranged from daily (Portugal and Spain) to yearly (Switzerland). The geographic area of data aggregation was national in Belgium, national, regional, and town/city in France 1 
and France 2, NUTS 1 and 3 in Germany, town/city in Italy 1 and Italy 2, national, regional, and NUTS 1 and 2 in Portugal, national, regional, and town/city in Spain, and national and NUTS 1 in Switzerland. The frequency with which the disseminated data were updated ranged from daily (Germany, Portugal, and Spain) to monthly (Italy 1 and Italy 2).
Privacy

Five systems (Belgium, France 1, France 2, Portugal, and Spain) collected personal data (i.e. data that can be used to directly or indirectly identify an individual), although none of them were authorised to provide personal data to other institutions.

\section{Strengths and weaknesses}

At the end of the questionnaire, we provided blank spaces for describing the system's strengths and weaknesses. The most commonly reported strengths were:

TABLE 2

Variables collected by the nine mortality surveillance systems, EuroMOMO survey, 2008

\begin{tabular}{|c|c|c|c|c|c|c|c|c|c|c|}
\hline System & Sex & Age & Age group & $\begin{array}{l}\text { Marital } \\
\text { status }\end{array}$ & $\begin{array}{l}\text { Date of } \\
\text { birth }\end{array}$ & $\begin{array}{l}\text { Date of } \\
\text { death }\end{array}$ & $\begin{array}{c}\text { Site of } \\
\text { death (e.g. } \\
\text { home, } \\
\text { hospital) }\end{array}$ & $\begin{array}{l}\text { Place of } \\
\text { death } \\
\text { (e.g. city, } \\
\text { region) }\end{array}$ & Residence & Nationality \\
\hline Belgium & $x$ & & & & $x$ & $x$ & & $x$ & $x$ & $x$ \\
\hline France 1 & $x$ & $x$ & & & & $x$ & & $x$ & $x$ & \\
\hline France 2 & $x$ & & & & $x$ & $x$ & $x$ & $x$ & $x$ & \\
\hline Germany & $x$ & $x$ & $x$ & & & $x$ & & $x$ & $x$ & \\
\hline Italy 1 & $x$ & & & & $x$ & $x$ & $x$ & $x$ & $x$ & \\
\hline Italy 2 & $x$ & $x$ & & & & $x$ & & $x$ & $x$ & \\
\hline Portugal & $x$ & $x$ & & & $x$ & $x$ & & $x$ & & \\
\hline Spain & $x$ & $x$ & & $x$ & $x$ & $x$ & $x$ & $x$ & $x$ & \\
\hline Switzerland & $x$ & $x$ & $x$ & & $x$ & $x$ & & $x$ & $x$ & $x$ \\
\hline
\end{tabular}

TABLE 3

Collection of data on influenza and climate by the mortality surveillance systems, EuroMOMO survey, 2008

\begin{tabular}{|c|c|c|c|c|c|}
\hline \multirow[b]{2}{*}{ System } & \multirow[b]{2}{*}{ Influenza data } & \multicolumn{4}{|c|}{ Climate data } \\
\hline & & $\begin{array}{c}\text { Minimum } \\
\text { temperature }\end{array}$ & $\begin{array}{l}\text { Maximum } \\
\text { temperature }\end{array}$ & Humidity & $\begin{array}{c}\text { Ozone/other } \\
\text { particles }\end{array}$ \\
\hline Belgium & $\mathrm{x}$ & $x$ & $x$ & $x$ & $x$ \\
\hline France $1^{\text {a }}$ & & $x$ & $x$ & $x$ & \\
\hline France $2^{\mathrm{a}}$ & & $x$ & $\mathrm{x}$ & $x$ & \\
\hline Germany & $x$ & $x$ & $x$ & & $x$ \\
\hline Italy $1^{\mathrm{b}}$ & & $x$ & $x$ & $x$ & - \\
\hline Spain & $x$ & $x$ & $x$ & & \\
\hline Switzerland $d^{\mathrm{a}, \mathrm{c}}$ & $x$ & $x$ & $x$ & & \\
\hline
\end{tabular}

${ }^{a}$ Climate data provided by another system/office.

${ }^{\text {b }}$ Also collects data on maximum apparent temperature.

c Influenza data provided by another system.

\section{TABLE 4}

Mode and frequency of data dissemination for the nine mortality surveillance systems, EuroMOMO survey, 2008

\begin{tabular}{|l|l|l|l|}
\hline System & Mode of data dissemination & Frequency of data dissemination & Period of aggregation for disseminated data \\
\hline Belgium & Public website & Weekly & Daily \\
\hline France 1 & Restricted website, email, hard copy & NR & Weekly \\
\hline France 2 & Email, hard copy & NR & weekly ('daily if necessary') \\
\hline Germany & NR & NR & daily, weekly \\
\hline Italy 1 & Email, hard copy & NR & Monthly \\
\hline Italy 2 & Public website & Every three months, annual report & Monthly \\
\hline Portugal & Email & Weekdays & Daily (though currently done only during summer) \\
\hline Spain & Email & Daily report, final summary report & Daily \\
\hline Switzerland & Public website, hard copy & Yearly & Weekly, monthly, yearly \\
\hline
\end{tabular}

NR: not reported. 
i) timeliness of data collection, ii) coverage, iii) usefulness of individual data for analyses by geographic area, age, sex, etc. and for linkage with influenza and climate data, iv) data quality, and v) low cost and ease of management of the system. The most commonly mentioned weaknesses were delay and the lack of data on the cause of death.

\section{Mortality surveillance systems in}

the pilot or planning phase

Six countries had what the contact persons defined as a 'pilot' system: Denmark, Germany (Berlin), Hungary, Ireland, the Netherlands, and Scotland. The start of the pilot phase in these countries was between 1995 and 2008 (information not available for Germany). In all cases, the system was managed by a health institute. Three systems had national coverage (Denmark, Ireland, and the Netherlands), and three collected data year-round (Denmark, Ireland, and Scotland). Only the system in Hungary collected influenza data, whereas climate data were collected by the systems in Ireland and Scotland. Only the system in Ireland recorded the specific cause of death. The median delay from the date of death to receipt of the data by the system was reported for two countries: three days in Denmark and 10 weeks in Ireland.

Another three countries had plans for a system: Greece, Sweden, and the United Kingdom. All of these systems were to be managed by a health institute. National coverage was expected for the systems in Sweden and the United Kingdom. The system in Sweden was planned to be operational for the entire year, and to collect also data on climate. Only the system in the United Kingdom was planned to collect influenza data, and cause of death was to be recorded by the systems in Greece and the United Kingdom.

\section{Routine collection of national mortality data}

The questionnaire included a space for a general description of the procedures for the routine collection of mortality data. Given that the descriptions greatly varied among the 30 countries that responded, a straightforward comparison was difficult, although the fundamental information was covered by the other sections of the questionnaire, reported below.

In 27 countries, a single standardised death certificate was used nationwide, 13 countries also used a separate perinatal death certificate. In addition, 20 of the 23 countries that recorded the specific cause of death also recorded contributory causes, i.e. other causes resulting in the underlying cause, and 19 recorded other significant conditions. The percentage of all death certificates for which more than one diagnosis was reported ranged from $25 \%$ to $98 \%$. Two countries used the ninth edition of the International Classification of Diseases (ICD-9) to codify the cause of death and 25 used ICD-10.
The main variables collected by each country are summarised in Table 5. Eleven countries collected additional variables (blank space designated as 'other' on the questionnaire), e.g. maternal death and performance of an autopsy.

Reporting delay was analysed by 11 countries, yet only four countries specified the 25 th, 50th and 75 th percentiles of the delay. The 5oth percentile of the delay ranged from one day (Spain) to 5.5 months (Cyprus). All countries performed data quality control, and almost all did so centrally. In 27 countries, the data collected were considered as personal data.

Regarding data dissemination, the year of the most recent publication ranged from 2000 to 2008. In all countries, the mortality data in the official national report were presented by sex. In 29 countries they were reported by age group, and in 26 countries they were reported in the form of rates.

\section{Discussion}

Mortality monitoring can be successfully used to identify public health threats, as demonstrated by the 122 Cities Mortality Reporting System in the United States [6] and, in Europe, by the use of mortality data for such threats as influenza outbreaks in France [7] and the effects of heat waves in the United Kingdom [8]. Although routinely collected vital statistics are accessible for all European countries, these statistics are in most cases not made available in a timely manner [2]. Moreover, a Europe-wide system for the timely monitoring of mortality does not exist, which will be especially important in identifying and addressing health events that go beyond national borders.

Only nine completely functioning systems for the timely monitoring of mortality currently existed in Europe at the time of our survey, and they represented only seven countries. That nearly all of them were managed by either a health or statistics institute is indicative of the type of expertise available, and that two thirds of the systems received specific funding is encouraging with regard to the financial resources available for surveillance.

The shortest median delay of reporting a death was four hours in France 2, thanks to the use of e-death certification. By contrast, the longest median delay was 10 days; whether or not this delay is acceptable for the purposes of EuroMOMO remains to be determined. Of concern is the finding that only three of the systems reported $100 \%$ coverage, and that the next highest coverage was only $57 \%$. In the next phase of EuroMOMO, means of improving and maintaining high coverage will have to be thoroughly discussed, along with the issue of achieving an acceptable balance of timeliness and high coverage. The importance of these two aspects was also highlighted by the fact that they were among the main strengths and weaknesses reported and that 


$$
\mid
$$


terms such as 'real-time' and 'early' were specified in some systems' objectives.

We were particularly concerned with whether or not the systems collected influenza data, in light of a potential influenza pandemic, as well as climate data, considering the importance of events such as heat waves and cold spells on mortality. Only about half of the systems monitored influenza mortality, while climate data were collected by nearly all of the systems during periods of potentially extreme climatic conditions (i.e. winter/ summer).

That some systems collected personal data raises the issue of data privacy, an increasing concern in light of the progress made in information technology and the consequent easy access to such data. Although none of the systems shared personal data with other institutions, a Europe-wide system will need to respect legislation on data protection such as 'Directive 95/46/ $\mathrm{EC}$ on the protection of individuals with regard to the processing of personal data and on the free movement of such data' and the specific legislation in individual countries [9].

The strengths and weaknesses pointed out for the different systems are not unusual for any surveillance system; nonetheless, they provide an indication of those characteristics that, according to the contact persons themselves, are fundamental, and, perhaps more importantly, those that are desired but have not yet been achieved. These responses will be essential when establishing (or adapting) systems in EuroMOMO.

Although described only briefly, the information on pilot and planned systems provides a useful indication of current and/or future resources for excess mortality monitoring. Moreover, systems that are not yet operating to their full intended potential or are still being planned are an opportunity to integrate the requirements of EuroMOMO, which may make these systems more attractive for inclusion in the EuroMOMO pilot phase. However, it must be considered that the pilot systems were defined as 'pilot' by the contact persons themselves.

All countries routinely collected national mortality data, albeit with different procedures and degrees of efficiency. A more detailed description of the collection of mortality data in Europe is provided in the latest Eurostat report, which however dates back to 2001 [4]. This information is relevant because the routine procedures could potentially serve as a basis to be adapted in situations requiring rapid mortality surveillance. In fact, one of the innovative aspects of EuroMOMO is that it will attempt to facilitate the use of routinely collected vital statistics in a new context, i.e for the timely surveillance of death, to support immediate public health action. However, this possibility would have to be thoroughly evaluated and may not always be feasible. The differences among European countries in the type of data collected and the data collection procedures present a major hurdle, although Eurostat has been committed to rendering these data as homogeneous and comparable as possible. It must also be considered that routine data collection is in many cases the responsibility of statistics institutes, whereas in our survey, more than half of the systems for monitoring excess mortality were run by a health institute. Therefore the potential for a statistics institute to run such a system or for different institutes to collaborate needs to be evaluated. However, perhaps the greatest challenge lies in making data collection rapid. Although routinely collected mortality data generally cover $100 \%$ of the population, they are not collected in a timely manner, at least not for the purposes of responding to a public health threat. Systems could be made more rapid by the use of automated procedures for data collection, such as the e-death certification used in the France 2 system, or by such simple means as sending data by fax, as done in the 122 Cities Mortality Reporting System [6]. However, these procedures could require additional resources, such as additional personnel and funding, which may not be available or not sufficient for covering the entire country. In fact, for the national France 2 system, the coverage in terms of the percentage of the population was only $1 \%$; for the 122 Cities Mortality Reporting System, although coverage is consistent (approximately 30\%), it is not exhaustive.

Some limitations of our survey need to be considered. Although we made every attempt to identify the most suitable contact persons, our response rate for the questionnaire on excess mortality monitoring was not $100 \%$. It is also possible that the responders were not aware of all existing mortality monitoring systems, although this is unlikely, given that an extensive network of healthcare professionals, including experts in death statistics and surveillance systems, was used to identify these persons. Moreover, some answers to the survey questions remained unclear or incomplete, although we repeatedly asked for clarification. Finally, collecting data through a system does not ensure they are of high quality, and although most of the systems monitoring excess mortality included data quality control, we did not investigate the specific control procedures.

Despite these limitations, the survey has provided an overall picture of excess mortality monitoring in Europe. There is room for improvement not only of the individual systems but more importantly of coverage of Europe as a whole. This knowledge will guide the next phases of EuroMOMO, in particular the identification of the minimum requirements for real-time mortality monitoring at the national and international level. Another EuroMOMO work package investigated the opinions of meteorological, public health, health and civil protection authorities on this matter, who all had different requirements (unpublished data). In particular, they distinguished between ideal requirements 
and minimum requirements, with the minimum requirements for a national system differing from those for a European system. They stated that the minimum requirements of a national system would have to consider the number of observed deaths, a baseline or a model, and allow data disaggregation at the regional level (NUTS II or finer) and by sex and age group. The minimum requirements at the European level were that the system had to consider the number of observed deaths, a baseline or a model, that it needed to have a weekly periodicity, and the ability to disaggregate data at the regional level (NUTS II). The ideal requirements should include meteorological data, clinical information on the deceased persons (e.g. pathological history and causes of death), and the ability to have data at the finest geographical level possible without breaking confidentiality.

As of October 200912 countries have been monitoring their weekly all-cause mortality using a common algorithm that was developed and pre-tested by EuroMOMO and that takes into account the inventory of mortality data and surveillance in Europe described in the present study. The algorithm generates indicators for excess mortality that are comparable across countries and offers a method to adjust for reporting delay. National outputs are submitted weekly to the project hub, where they are compiled and published in a weekly European bulletin. During the pilot phase, the bulletin is only available to a restricted audience, as the outputs are not validated and could thus be artificial. Despite being a pilot system subject to the mentioned limitations, EuroMOMO was recognised as an invaluable tool for monitoring severity during the 2009 influenza $A\left(\mathrm{H}_{1} \mathrm{~N}_{1}\right)$ pandemic.

\section{Acknowledgements}

This project receives funding from the European Commission (DG SANCO). Neither the European Commission, nor any person acting on its behalf is liable for any use made of the information published here. We wish to thank Anne Mazick for her invaluable contribution to this work.

\section{References}

1. Kaiser R, Coulombier D, Baldari M, Morgan D, Paquet C. What is epidemic intelligence, and how is it being improved in Europe? Euro Surveill 2006;11(5): $p i i=2892$. Available from: http://www.eurosurveillance.org/ViewArticle. aspx?Articleld $=2892$

2. Mazick A, Participants of a workshop on mortality monitoring in Europe. Monitoring excess mortality for public health action: potential for a future European network. Euro Surveill. 2007;12(1):pii=3107. Available from: http://www. eurosurveillance.org/ViewArticle. aspx?Articleld=3107

3. EuroMOMO. European Monitoring of Excess Mortality for Public Health Action. Homepage on the internet. Available from: www. euromomo.eu

4. Centre d'épidémiologie sur les causes médicales de décès (CépiDc), French Institute for Health and Medical Research (Inserm). Comparability and quality improvement in European causes of death statistics. Final report. Brussels: European Commission DG SANCO; July 2001. Report No. EDC DGV/F3 SOC 98 20108. Available from: http://www.cepidc.vesinet.inserm. $\mathrm{fr} /$ inserm/html/pdf/fp_monitoring_1998_frep_04_en.pdf
5. Eurostat. Nomenclature of territorial units for statistics. Brussels: European Commission Eurostat. Available from: http://epp.eurostat.ec.europa.eu/portal/page/portal/nuts nomenclature/introduction. [Accessed 28 September 2010].

6. Simonsen L, Clarke MJ, Stroup DF, Williamson GD, Arden $\mathrm{NH}, \mathrm{Cox}$ N. A method for timely assessment of influenzaassociated mortality in the United States. Epidemiology. 1997;8(4):390-5.

7. Josseran L, Nicolau J, Caillère N, Astagneau P, Brücker G. Syndromic surveillance based on emergency department activity and crude mortality: two examples. Euro Surveill. 2006;11(12): $\mathrm{pii}=668$. Available from: http://www. eurosurveillance.org/ViewArticle.aspx?Articleld=668

8. Johnson H, Kovats RS, McGregor G, Stedman J, Gibbs $M$, Walton $H$. The impact of the 2003 heat wave on daily mortality in England and Wales and the use of rapid weekly mortality estimates. Euro Surveill. 2005;10(7): pii=558. Available from: http://www.eurosurveillance.org/ViewArticle. aspx?Articleld $=558$

9. Directive $95 / 46 / \mathrm{EC}$ on the protection of individuals with regard to the processing of personal data and on the free movement of such data; http://eur-lex.europa.eu/LexUriServ/LexUriServ. do?uri=CELEX:31995Lo046:EN:HTML; last visited 1 October 2010 